\title{
Н. Гегелашвили
}

\section{АРМЕНИЯ И США: НОВЫЙ ЭТАП СОТРУДНИЧЕСТВА*}

DOI: 10.20542/2073-4786-2019-2-127-140

\section{Интересы Вашингтона в отношении стран Закавказья}

Постсоветские государства продолжают переживать трансформацию, связанную с происходящими там сложными внутренними процессами и с пересмотром своих внешнеполитических приоритетов. В значительной степени это касается как региона Закавказья в целом, так и Армении. Все три государства Закавказья - Грузия, Азербайджан и Армения - интересуют США, прежде всего в контексте ближневосточной проблематики, проблемы Ирана, вопросов энергетической безопасности, расширения НАТО на Восток. Это в значительной степени и определяет приоритеты Вашингтона в отношении государств региона.

Внутренние перемены в Армении, приведшие к смене власти в республике, как и заявка нового премьер-министра Н.Пашиняна «на радикальные изменения внутри страны и укрепление ее внешнеполитической самостоятельности» [1] создали здесь, с точки зрения США, «превосходные перспективы для более стабильной демократии» [2]. В значительной степени это способствует обновлению американской политики на армянском направлении, и не исключено, что Ереван может стать сферой особых интересов сегодняшнего Вашингтона. Как представляется, это может быть обусловлено следующими факторами.

Во-первых, активизацией политики США в регионе в целом, и в Армении в частности, в связи с украинским кризисом и событиями в Сирии.

Во-вторых, с учетом того, что Армения - единственная страна в 3акавказье, являющаяся как членом Евразийского экономического союза (ЕАЭС), так и Организации договора о коллективной безопасности (ОДКБ), и что на ее территории расположена российская военная база Гюмри, - она имеет большое значение для Москвы с точки зрения ее стратегических интересов на Кавказе. Это идет вразрез с курсом США на недопущение альтернатив американскому доминированию в мире, который распространяется и на регион Закавказья.

\footnotetext{
* Статья подготовлена при финансовой поддержке Российского фонда фундаментальных исследований по проекту № 17-07-00011
} 
В-третьих, с подписанием Конвенции о правовом статусе Каспийского моря [3] выход к Каспию для США был практически заблокирован, по крайней мере, в настоящее время, что повышает интерес Вашингтона к региону с учетом совместных проектов, касающихся всего Причерноморья.

B-четвертых, с учетом внешнеполитических приоритетов Грузии, ориентированной на интеграцию с евроатлантическими структурами, и относительно независимой позиции Азербайджана, дрейф Армении от РФ в сторону Запада может серьезно изменить расстановку сил в Закавказье, что недопустимо с точки зрения стратегических интересов Москвы в регионе.

Поэтому, очевидно, что подход сегодняшнего Вашингтона к Еревану будет меняться в рамках общего обновления американской политики в Закавказье.

\section{Основные приоритеты политики Вашингтона в отношении Армении}

В поздравительном послании Николу Пашиняну в связи с его избранием на пост премьер-министра Армении президент Трамп заявил, что «Соединенные Штаты поддерживают процветающую, демократическую и мирно сосуществующую с соседями Армению» и что «обе страны могут добиться прогресса в углублении торговли, укреплении глобальной безопасности и борьбе с коррупцией. Мирное урегулирование нагорнокарабахского конфликта поможет этим усилиям» [4]. Это послание определило основные направления американской политики в этой стране. Вот почему США сделали основной упор на развитии экономики и укреплении безопасности, что может стать своего рода прелюдией на пути дальнейшего вовлечения Армении в сферу интересов Вашингтона.

В настоящее время Армения получила от США ряд предложений, связанных с поставками ей современных вооружений, призванных укрепить ее оборонный потенциал, и инвестициями в экономику страны, способными сделать ее открытой для внешнего мира. Расчеты Вашингтона связаны с получением позитивной реакции Еревана на инвестиционные предложения США, что в дальнейшем может определять политику администрации Трампа в этой стране.

Предложения Еревану со стороны администрации Трампа касаются и такого актуального для Армении вопроса, как продажа ей американских вооружений, которые, по утверждению Вашингтона, «превосходят российские». Это, с точки зрения США, позволит Еревану «не зависеть полностью ни от одной крупной державы», и «прежде всего от России, являющейся ключевым поставщиком» [5]. Более того, США предупредили Армению об угрозе возможных санкций в случае «существенных сделок» с российскими 
военно-промышленными компаниями, включенными в американский санкционный список [6].

Показательно, что параллельно с этим администрация Трампа рассматривает возможность отмены действия 907-й поправки к «Акту в поддержку свободы», ограничивающей оказание американской помощи Азербайджану на государственном уровне [7]. Это необходимо Вашингтону для того, чтобы в случае «провальной» сделки по продаже оружия Еревану возможность отмены этой поправки могла бы придать отношениям США с Азербайджаном новый импульс, хотя и сегодня Баку является крупнейшим в регионе покупателем американского оружия и надежным стратегическим партнером Вашингтона.

Очевидно, что нынешняя администрация США будет уделять особое внимание развитию армяно-иранских отношений. В целом США стремятся минимизировать роль Ирана не только на Ближнем Востоке, но и на Кавказе в целом, в том числе - в Армении, особенно с учетом существования общей границы двух государств. При этом, с одной стороны, в Ереване осознают, что намерения Вашингтона в отношении Тегерана, связанные с оказанием на него давления для изменения его «зловредного поведения» более чем серьезны, а игнорирование мер, принятых США против Ирана, может обернуться против Армении санкциями со стороны Вашингтона. С другой стороны, в условиях сухопутной блокады, в которой в настоящее время находится Армения, Иран обеспечивает ей выход во внешний мир, и обе страны связывают прочные торгово-экономические отношения. Как представляется, в этих условиях Еревану будет крайне сложно продолжать на данном направлении свою комплементарную политику.

Об активизации политики Вашингтона в Закавказье в целом, и в Армении в частности, наглядно свидетельствует и число визитов чиновников США из высших эшелонов власти. Сразу после «бархатной революции» 27 28 мая 2018 г. Армению посетила заместитель помощника Госсекретаря США по делам Европы и Евразии Бриджит Бринк, которая в ходе встреч с высшими должностными лицами этой страны заявила, что «Соединенные Штаты привержены сотрудничеству с новым правительством РА в целях укрепления двусторонних связей, и, как страна-сопредседатель Минской группы ОБСЕ, США будут и впредь поддерживать мирное урегулирование карабахского конфликта» [8]. 15 октября 2018 г. Армению посетил другой заместитель помощника госсекретаря США по делам Европы и Евразии Джордж Кент, заявивший, что «США готовы помочь властям Армении в процессе осуществления реформ» [9].

Однако наиболее примечательным событием стал визит советника президента США по национальной безопасности Джона Болтона, состоявшийся 25 октября 2018 г. в рамках его кавказского турне, куда были вклю- 
чены все три страны Закавказья. Визит был призван оценить «значимую географическую роль», которую Армения, Азербайджан и Грузия играют в отношениях с Ираном, Россией и Турцией, что предопределяет интерес американский администрации к этому региону. В своем твиттере Болтон отметил, что целью его визита будет ряд встреч «с партнерами, а также высшими государственными чиновниками для продвижения американских интересов по широкому кругу вопросов безопасности». Было также заявлено об усилении роли Вашингтона как сопредседателя Минской группы ОБСЕ в вопросе урегулирования нагорно-карабахского конфликта» [10].

В настоящее время администрация Трампа придает большое значение развитию военно-политических отношений с Арменией не только в контексте двусторонних отношений, но и отношений Еревана с НАТО. Отнюдь не случайно, что, согласно заявлению недавно покинувшего Армению посла США в этой стране Ричарда Миллза, «Вашингтон хотел бы наделить Армению инструментами, позволяющими ей принимать суверенные решения и быть уверенным, что она не подвергнется давлению со стороны других стран с целью следования тому пути, по которому Армения идти не желает» [11].

Таким образом, похоже, что Североатлантический альянс будет использовать все возможные инструменты для усиления военного потенциала всех стран Закавказья, чтобы «противостоять агрессии со стороны России». Помощь США в сфере безопасности в регионе призвана способствовать реформам в области обороны и военной модернизации, а также расширению возможностей стран региона действовать совместно с силами США и НАТО. Следующим этапом политики Вашингтона в отношении Еревана на пути его сближении с Альянсом может стать усиление натовской составляющей, которое, на взгляд США, должно осуществляться параллельно с оказанием американской поддержки в области проведения военных, гражданских и социальных реформ.

Но и сегодня Армения не находится «в стороне от столбовой дороги» НАТО. В настоящее время Ереван участвует в программе ПРМ «Партнерство во имя мира» (Partnership for Peace - PfP) в рамках ежегодной Программы индивидуального партнерства (Annual Individual Partnership Programme - IPP). В рамках программы ПРМ и Совета евроатлантического партнерства (СЕАП) Армения также сотрудничает и с другими странамипартнерами альянса [12]. В рамках ПРМ Армения, начиная с 2002 г., также участвует в Процессе планирования и анализа (ПРА) - Planning and Review Process (PARP), что призвано содействовать развитию ее отдельных военных формирований во взаимодействии с силами HATO. При этом PARP занимает центральное место в сотрудничестве Армении с альянсом [12]. 
Партнерство Еревана с НАТО способствует достижению оперативной совместимости вооруженных сил республики со странами альянса. Обе стороны активно проводят консультации по вопросам, связанным с реформированием системы военного образования в Армении. В этой связи следует также отметить, что Армения внесла важный вклад в осуществляемую в Афганистане миссию НАТО - Международные силы содействия безопасности (ISAF) в 2004 г., а с февраля 2010 г стала участвовать и в миротворческой миссии альянса в Косово «Силы для Косово» (СДК) (KFOR) [12].

Таким образом, не исключено, что, с учетом опыта Грузии, НАТО может утвердить пакет «усиленного сотрудничества» с Арменией, предусматривающий оказание всесторонней помощи на пути обретения ею членства в альянсе, что может перевести отношения обеих сторон на новый уровень. Началом этого может стать открывшийся в октябре 2017 г. после капитального ремонта учебный центр «Зар», финансовую поддержку в реконструкции которого оказала американская сторона.

Центр является основным учебным подразделением миротворческой бригады Министерства обороны РА, в котором проводятся учения и переподготовка армянских военнослужащих для участия в международных миротворческих миссиях. Пока основное отличие центра «Зар» от другого учебно-тренировочного центра НАТО, расположенного в Грузии (Крцаниси), заключается в его статусе. Если учебный центр в Грузии призван способствовать подготовке не только грузинских военных, но и военных стран Альянса и его партнеров, то на данном этапе учебный центр в Армении предназначен лишь для выполнения учебных задач, стоящих перед миротворческими силами МО Армении.

Однако не исключено, что в перспективе открытие совместного центра может создать новые возможности в области двустороннего сотрудничества, направленного в первую очередь на усиление обороноспособности этой страны. Показательно, что в августе 2018 г. Армения впервые приняла участие в многонациональных военных учениях под эгидой HATO - "Noble Partner 2018” (“Достойный партнер - 2018”), что может свидетельствовать о намерении Еревана участвовать в подобных мероприятиях и в дальнейшем.

В этой связи важно отметить, что с учетом состоявшихся 3-11 сентября 2017 г. в Грузии многонациональных военных учений «Проворный дух 2017» (Agile Spirit 2017), особого внимания заслуживает ситуация, возникшая в связи с заявкой Еревана на участие в них, которая за несколько дней до учений была дезавуирована. Несмотря на то что стратегическая цель Армении заключается в развитии отношений с НАТО, тем не менее игнорировать российский фактор Ереван на тот момент не мог.

Однако похоже, что ситуация меняется. В рамках состоявшихся 1115 марта 2019 г. в Армении мероприятий Недели НАТО, в Ереван прибыл 
спецпредставитель Генсека Альянса по странам Южного Кавказа и Центральной Азии Джеймс Аппатурай. В ходе его визита состоялась встреча с министром обороны Армении Давидом Тонояном, на которой обсуждались перспективы сотрудничества Альянса с Арменией.

Особое внимание было уделено сотрудничеству сторон в сфере оборонных реформ и образования, участию Еревана в миссиях НАТО по обеспечению мира и стабильности в Косово и Афганистане. Были затронуты вопросы, связанные и с урегулированием нагорно-карабахского конфликта, который согласно заявлению Аппатурая «надо решать исключительно мирным путем» [13], а также проблемы региональной безопасности.

Характерно, что при этом официальный Ереван на всех уровнях продолжает подчеркивать, что «является лишь партнером НАТО». В то же время очевидно и то, что развитие сотрудничества Армении с Альянсом будет способствовать расширению спектра возможностей НАТО в этой стране и в самом регионе.

\section{Проблема урегулирования нагорно-карабахского конфликта}

Вашингтон заинтересован в продвижении финансируемых им экономических и энергетических проектов, а значит - в разрешении существующих кавказских конфликтов и предотвращении новых, которые могут воспрепятствовать реализации таких проектов. Вот почему в настоящее время внимание США направлено на урегулирование нагорно-карабахского конфликта и на укрепление региональной безопасности в целом.

В своем послании, адресованном премьер-министру Армении Николу Пашиняну по случаю Дня независимости Армении, президент Трамп так обозначил американскую позицию в отношении перспектив урегулирования нагорно-карабахского конфликта: «В ближайшие месяцы открываются возможности для его урегулирования, что может придать новый импульс развитию армяно-американских отношений. США как страна - сопредседатель Минской группы ОБСЕ готовы работать с вами вокруг поиска долгосрочного мирного решения конфликта» [14].

Это послание тесно коррелируется с заявлением посетившего Ереван в октябре 2018 г. советника президента США по национальной безопасности Джона Болтона, согласно которому «нынешние обстоятельства подчеркивают важность нахождения взаимовыгодного соглашения по нагорнокарабахскому вопросу, потому что, как только это произойдет, откроется армяно-азербайджанская граница. Турецкая граница, я считаю, почти наверняка откроется. И я думаю, что граница с Грузией может быть менее подвержена озабоченностям в связи с тем давлением, которое Россия может оказывать на них» [15]. 
Таким образом, очевидно стремление США найти такое решение, при котором Армения, Азербайджан и Турция должны быть самым тесным образом связаны с Западом, чтобы у России было меньше возможностей для «оказания давления» на страны Закавказья.

Представляется, что Вашингтон намерен активизировать свои посреднические усилия по урегулированию карабахского конфликта, заняться решением этой проблемы самостоятельно в рамках реализации своей политики на закавказском направлении. Косвенными признаками форсирования проблемы урегулирования конфликта являются, во-первых, признание Вашингтоном того факта, что в настоящее время «статус-кво является неприемлемым и не может продолжаться вечно» и что «любое урегулирование карабахского конфликта потребует возвращения части оккупированных территорий, хотя такие события, как апрельская война 2016 г., делают это еще более затруднительным для армянского народа» [16].

Во-вторых, ряд резолюций, центральными из которых является инициированная Конгрессом США 115 созыва Резолюция 573 [17], призывающая администрацию Трампа к выстраиванию более справедливых и долгосрочных армяно-турецких отношений, а также Резолюция 190 [18] Конгресса нового, 116 созыва, выражающая поддержку развитию отношений между США и Республикой Арцах (так после референдума 2017 г. называется Нагорно-Карабахская Республика), подтверждают намерение Вашингтона сдвинуть ситуацию в обеих странах с мертвой точки и стать главным модератором конфликта.

Таким образом, осознавая то значение, которое имеет для Армении урегулирование нагорно-карабахского конфликта, интересы США на армянском направлении будут прежде всего направлены на нормализацию турецко-армянских отношений и, как результат, - открытие армяно-турецкой границы, что будет иметь стратегическое значение для Вашингтона, особенно в условиях дальнейшего обострения американо-иранских отношений. Именно решение этих вопросов позволит и дать старт урегулированию конфликта.

США и ранее предпринимали попытку пересмотра двусторонних отношений с Арменией, что нашло отражение в посреднической миссии Вашингтона, когда он пытался разрешить крайне непростые противоречия между Арменией и Турцией. Несмотря на подписание 10 октября 2009 г. в Цюрихе главами МИД Турции и Армении Ахметом Давутоглу и Эдвардом Налбандяном «Цюрихских протоколов» [19] о нормализации турецкоармянских связей, предусматривающих установление дипломатических отношений, открытие сухопутной границы (более 300 км) и т. д., что позволило бы начать сотрудничество двух стран, они так и не были ратифицированы сторонами и не вступили в силу. 
Главная причина провала посреднической миссии США на этом направлении состояла в том, что Вашингтон продолжает рассматривать карабахский конфликт и вопрос армяно-турецких отношений в отрыве друг от друга, и это стало очередным препятствием для продолжения диалога. США, выступившие в роли вдохновителя Цюрихских протоколов о нормализации турецко-армянских отношений, так и не смогли убедить азербайджанское руководство в том, что процесс нормализации армяно-турецких отношений и карабахское урегулирование могут рассматриваться отдельно друг от друга. Баку настоял на своем, и Анкара заявила, что границы с Арменией откроются лишь после того, как Ереван приступит к освобождению оккупированных азербайджанских территорий.

Таким образом, стремление США к нахождению компромисса, необходимого для обеих сторон конфликта - Азербайджана и Армении, вполне очевидно и, в случае успеха, может способствовать развитию сотрудничества Еревана с Баку и, как результат, - с Турцией, что положит конец региональной изоляции Армении. Такое положение дел подогревает стремление Еревана к активизации западного вектора внешнеполитического курса, что полностью совпадает с интересами Вашингтона в отношении Армении. Похоже, что США будут всячески поддерживать западные устремления Еревана, используя для этого все необходимые средства.

В то же время, сегодня США усомнились в целесообразности процесса урегулирования этого конфликта, что подтверждается крайне неэффективной, с их точки зрения, работой Минской группы ОБСЕ. Она была создана специально для поиска компромисса в самом сложном этнотерриториальном конфликте в Закавказье, где США, наряду с Россией и Францией, являются сопредседателем. При этом Вашингтон и Москва рассматривают «Обновленные Мадридские принципы» [20] как основу для мирного решения. Однако, в отличие от Вашингтона, Москва в настоящее время не спешит изменить статус-кво, исходя из того, что любое его изменение без ее участия может быть направлено против интересов России.

К тому же опасения российской стороны, связанные с изменением статус-кво, подкрепляются стремлением Запада к интернационализации конфликтов на постсоветском пространстве при снижении роли Москвы и без учета ее особых интересов. Отсюда - разочарованность Баку и Еревана в политике Москвы, направленной на сохранение статус-кво, а не компромиссное урегулирование конфликта.

В целом как Азербайджан, так и Армения готовы вести переговоры по «Обновленным Мадридским принципам» и рассматривают их как основу для мирного решения. Однако «Обновленные Мадридские принципы» затрагивают крайне чувствительные для Армении вопросы и прежде всего определение международно-правового статуса Нагорного Карабаха. Азер- 
байджан последовательно придерживается позиции, согласно которой урегулирование конфликта возможно лишь при сохранении его территориальной целостности, предполагающей непременное восстановление юрисдикции над территорией Нагорного Карабаха. Это условие и стало главным препятствием на пути решения конфликта. Еще одним важным вопросом для Еревана является возвращение Баку семи районов, прилегающих к Нагорному Карабаху, которые ныне подконтрольны армянским силам.

В настоящее время активность Вашингтона, связанная с перспективами урегулирования конфликта, растет в геометрической прогрессии. С начала 2019 г. состоялся ряд встреч между министрами иностранных дел этих двух стран и между премьер-министром Армении и президентом Азербайджана. Две первые встречи между министрами иностранных дел Зограбом Мнацаканяном и Эльмаром Мамедъяровым, состоявшиеся 11 июля 2018 г. в Брюсселе во время саммита НАТО, а также 26 сентября 2018 г. в Нью-Йорке в ходе сессии Генассамблеи ООН, прошли при посредничестве сопредседателей Минской группы ОБСЕ и стали своего рода подготовкой к их третьей встрече. Она состоялась 16 января 2019 г. в Париже при посредничестве сопредседателей той же Минской группы ОБСЕ.

Показательно, что на этой встрече главы МИД двух стран общались более четырех часов, что дало основание для предположения об активизации мирного процесса и возможности принятия некоего решения, связанного с обсуждением возможных сценариев мирного урегулирования в среднесрочной перспективе. Не случайно, что именно эта встреча получила высокую оценку со стороны сопредседателей Минской группы ОБСЕ. В своем заявлении они выразили признательность 3.Мнацаканяну и Э.Мамедъярову «за продолжающиеся усилия по поддержанию атмосферы, благоприятствующей интенсивным переговорам, ориентированным на достижение конкретных результатов» [21].

Параллельно с этим проходили встречи и между премьер-министром Армении Николом Пашиняном и президентом Азербайджана Ильхамом Алиевым - 22 января 2019 г. в Давосе на полях Всемирного экономического форума прошла их неформальная встреча, уже третья в таком формате. В ходе переговоров лидеры двух стран договорились о создании каналов «быстрой связи» - механизмов прямой связи друг с другом - для установления оперативных контактов в случае чрезвычайных ситуаций на линии соприкосновения армянских и азербайджанских войск. Тем не менее все эти встречи проходили лишь на площадках различных международных форумов. Их первая официальная встреча, на которой обсуждались вопросы, связанные с урегулированием карабахского конфликта, состоялась в Вене 29 марта 2019 г. 
Показательно, что в интервью телекомпании «Аль-Джазира» Н.Пашинян заявил о готовности «встретиться лицом к лицу с президентом Азербайджана с целью урегулирования карабахского конфликта» [22]. Прелюдией к этому стала «ознакомительная встреча» между Э.Мамедъяровым и новым министром иностранных дел 3.Мнацаканяном, состоявшаяся 11 июля 2018 г. в Брюсселе, и тот факт, что Ереван не стал акцентировать тему непременного участия Степанакерта в мирном процессе, тем самым демонстрируя готовность к уступкам там, где это необходимо.

Таким образом, основными подвижками на пути урегулирования конфликта стало проявление готовности сторон встретится друг с другом и возвращение «Обновленных Мадридских принципов» в повестку переговоров. Это дало повод наблюдателям говорить о возможности скорого достижения компромисса, связанного с возвратом Азербайджану занятых территорий, созданием коридора, связывающего Армению с Нагорным Карабахом, и др.

В то же время, сегодня вопросу о необходимости включения непризнанной НКР в переговорный процесс, являющемуся ключевым для Степанакерта, стало уделяться большее значение, несмотря на то, что чрезмерная обособленность позиции и самостоятельность Нагорного Карабаха вызывает у официального Еревана некоторое раздражение, которое он пытается по возможности нивелировать. Такое положение дел диктуется реалиями времени, тем более, что в Армении постоянно ведутся дискуссии о целесообразности участия непризнанной НКР в переговорном процессе. Как представляется, актуализация вопроса, связанного с прямым участием Степанакерта в мирном процессе, может быть тесно связана с осознанием Ереваном того факта, что его возможные уступки в отношении Нагорного Карабаха могут вызвать жесткие обвинения в адрес правящей власти со стороны консервативно настроенной части армянского общества и привести к непредсказуемым последствиям.

Таким образом, аргумент, что реальных переговоров не будет, пока в них не участвует Карабах, стал звучать более убедительно. Весьма показательным в этом отношении было заявление Н.Пашиняна во время прессконференции в ходе его посещения Арцаха 9 мая 2018 г. на следующий день после избрания его премьером: он готов вести переговоры с президентом Азербайджана И.Алиевым от имени Армении, в то время как руководству НКР следует вести переговоры от имени карабахской стороны [23]. Такой маневр позволяет Пашиняну, с одной стороны, дистанцироваться от этой проблемы настолько, насколько это возможно, а с другой - дает шанс для укрепления своих позиций внутри страны.

Тем не менее сегодня Ереван ставит своей ключевой задачей в вопросе урегулирования конфликта привлечение Нагорного Карабаха к перегово- 
рам в качестве полноправного участника, демонстрируя, что, несмотря на свою готовность к переговорам с Азербайджаном, никаких компромиссов он не допустит.

Таким образом, именно вопрос об участии Нагорного Карабаха в переговорном процессе может стать основным камнем преткновения на пути урегулирования конфликта как со стороны самого Нагорного Карабаха, выступающего за свое непременное участие в переговорах, так и со стороны Баку, который против такого участия. Согласно позициям стран - сопредседателей Минской группы ОБСЕ, все они приветствуют любую инициативу, поддерживаемую на основе компромисса всеми участниками мирного процесса. Однако изменять формат переговоров, на участии в которых настаивает Степанакерт, они не смогут, так как эта проблема выходит за рамки их компетенции и является исключительно прерогативой политиков. Сами же первые лица стран, вовлеченных в процесс урегулирования, при всем осознании важности этой проблемы, не готовы сделать ее первостепенным вопросом своей внешнеполитической повестки.

В этой ситуации посредническая миссия России, связанная с проблемой урегулирования самого нагорно-карабахского конфликта, в целом, и с решением данного вопроса, в частности, может стать определяющей при выстраивании Москвой своей политики на армянском направлении. Ведь в настоящее время ни ЕС, ни НАТО не могут дать Армении тех гарантий безопасности, которые обеспечивает Россия как на границе с Турцией, так и в нагорно-карабахском конфликте. К тому же, урегулирование конфликта является одним из важных направлений внешнеполитических усилий РФ, и Москва занимает ключевую позицию в его решении, пытаясь заинтересовать обе стороны в соблюдении перемирия в условиях трансформации конфликта.

Показательно, что способность Москвы сохранять в этих условиях баланс сил, несмотря на конфронтацию между Россией и США, находит поддержку у Запада, что подтверждает ее особую роль в процессе мирного урегулирования. К тому же внешнеполитический курс Армении, основанный на двух принципах - комплементаризм (взаимодополняемость), позволяющий Еревану балансировать между всеми внешнеполитическими партнерами, не противопоставляя их друг другу, и вовлеченность (интегрированность), предполагающая свободное и неограниченное участие в международных и региональных структурах, - будет строиться исключительно на прагматических, а потому взаимовыгодных интересах. Однако этот курс имеет разумные пределы, и в самой Армении прекрасно понимают это. 


\section{СПИСОК ЛИТЕРАТУРЫ}

1. A Turning Point in Armenia's Foreign Policy. The Armenian Weekly. 12.03.2018. URL: https://armenianweekly.com/2019/03/12/a-turning-point-inarmenias-foreign-policy/ (дата обращения 20.04.2019).

2. Bolton Vows To 'Squeeze Iran,' Explore Weapons Sales to Armenia. The Armenian Mirror-Spectator. 30.10.2018. URL: https://mirrorspectator.com/2018/10/30/bolton-vows-to-squeeze-iran-exploreweapons-sales-to-armenia/ (дата обращения 19.04.2019).

3. Конвенция о правовом статусе Каспийского моря. Президент России. 12.08.2018. URL: http://www.kremlin.ru/supplement/5328 (дата обращения 19.04.2019).

4. Trump congratulates Pashinyan on election as Prime Minister of Armenia. EurAsia Daily. 16.05.2018. URL: https://eadaily.com/en/news/2018/05/16/trumpcongratulates-pashinyan-on-election-as-prime-minister-of-armenia (дата обращения 15.12.2018).

5. U.S. Embassy in Armenia. John Bolton Interview with Radio Free Europe/Radio Liberty (RFE/RL). 25.10.2018. URL: https://am.usembassy.gov/bolton-rferl-interview/(дата обращения 15.10.2018).

6. В Армении видят риски в санкциях США из-за оружейных сделок с Россиeŭ. Regnum. 14.02.2018. URL: https://regnum.ru/news/2380465.html / (дата обращения 7.10.2018).

7. U.S. Congress. S.2532 - FREEDOM Support Act. 24.10.1992. URL: https://www.congress.gov/bill/102nd-congress/senate-bill/2532/text/ (дата обращения 13.03.2018).

8. Президент Армении и представитель Госдепа США обсудили двусторонние отношения. TACC. 28.05.2018. URL: https://news.rambler.ru/conflicts/39956931-prezident-armenii-i-predstavitelgosdepa-ssha-obsudili-dvustoronnie-otnosheniya// (дата обращения 20.07.2018). 9. Премьер-министр принял заместителя помощника госсекретаря США: собеседники обменялись мнениями по урегулированию нагорнокарабахского конфликта и ряду других вопросов. Tert.Am. 15.10.2018. URL: https://www.tert.am/ru/news/2018/10/15/gov/2819361// (дата обращения 20.11.2018).

10. John Bolton Twitter. 11.10.2018. URL: https://twitter.com/ambjohnbolton/status/1050512147657252865/ (дата обращения 19.10.2018).

11. США хотят дать Армении инструментарий «для принятия суверенных решений». EurAsia Daily. 26.08.2017. URL: https://eadaily.com/ru/news/2017/08/26/ssha-hotyat-dat-armenii-instrumentariydlya-prinyatiya-suverennyh-resheniy// (дата обращения 19.04.2019). 
12. North Atlantic Treaty Organization. Relations with Armenia. 08.11.2018. URL: https://www.nato.int/cps/en/natohq/topics_48893.htm// (дата обращения 19.04.2019).

13. James Appathurai: NATO supports peaceful settlement of Nagorno-Karabakh conflict. News.Am. 11.03.2019. URL: https://news.am/eng/news/500657.html// (дата обращения 19.03.2019).

14. President Trump congratulates PM Pashinyan. I hope our partnership that started 100 years ago will further strengthen. Horizon. 20.09.2018. URL: https://horizonweekly.ca/fr/president-trump-congratulates-pm-pashinyan-i-hopeour-partnership-that-started-100-years-ago-will-further-strengthen/ (дата обращения 30.11.2018).

15. After Bolton takes aim at Russia and Iran, is Armenia the collateral damage? Eurasianet. 30.10.2018. URL: https://eurasianet.org/after-bolton-takes-aim-atrussia-and-iran-is-armenia-the-collateral-damage// (дата обращения 15.12.2018). 16. Ричард Миллз: Урегулирование карабахского конфликта потребует возвращения части «оккупированных территорий». Versia.Am. 17.10.2018. URL: http://www.versia.am/richard-millz-uregulirovanie-karabaxskogo-konfliktapotrebuet-vozvrashheniya-chasti-okkupirovannyx-territorij/ (дата обращения 15.12.2018).

17. H.Res.573 - Calling on the President to work toward equitable, constructive, stable, and durable Armenian-Turkish relations based upon the two countries' common interests and the United States' significant security interests in the region. 115th Congress (2017-2018). Congress.Gov. 12.10.2017. URL: https://www.congress.gov/bill/115th-congress/house-resolution/573// (дата обращения 15.11.2018).

18. H.Res.190 - Expressing the sense of the House of Representatives supporting visits and communication between the United States and the Republic of Artsakh at all levels of civil society and government. 116th Congress (2019-2020). Congress.Gov. 07.03.2019. URL: https://www.congress.gov/bill/116thcongress/house-

reslution/190/text?q=\%7B $\% 22$ search $\% 22 \% 3 \mathrm{~A} \% 5 \mathrm{~B} \% 22$ Azerbaijan $\% 22 \% 5 \mathrm{D} \% 7 \mathrm{D}$ $\& \mathrm{r}=1 \& \mathrm{~s}=1 /$ (дата обращения 20.03.2019).

19. Протокол о развитии двусторонних отношений между Республикой Армения и Турецкой Республикой. Кавказский Узел. 11.11. 2009. URL: https://www.kavkaz-uzel.eu/articles/162983// (дата обращения 27.03.2019).

20. A New Look at Old Principles: Making the Madrid Document Work. - Caucasus Edition: Journal of Conflict Transformation. 01.04.2011. URL: http://caucasusedition.net/why-nagorno-karabakhs-status-must-be-addressed-first/ (дата обращения 27.04.2017)

21. Joint Statement by the Heads of Delegation of the OSCE Minsk Group CoChair Countries, Armenia, and Azerbaijan. Organization for Security and Co- 
operation in Europe (OSCE). 06.12.2018. URL: https://www.osce.org/minskgroup/405479/ (дата обращения 10.01.2019).

22. Я готов встретиться с президентом Азербайджана Ильхамом Алиевым лицом к лицу: Пашинян. Armtimes.com. 26.07.2018. URL: https://armtimes.com/ru/article/142337 (дата обращения 10.08.2018)

23. «Карабахские тезисы» Пашиняна: НКР за столом переговоров без признания? Russia-Armenia info. 11.05.2018. URL: http://russiaarmenia.info/node/49017/// (дата обращения 17.05.2018). 